\title{
Comparison of aromatic hydrocarbon measurements made by PTR-MS, DOAS and GC-FID during the MCMA 2003 Field Experiment
}

\author{
B. T. Jobson ${ }^{1}$, R. A. Volkamer ${ }^{2,4}$, E. Velasco ${ }^{3}$, G. Allwine ${ }^{1}$, H. Westberg ${ }^{1}$, B. K. Lamb $^{1}$, M. L. Alexander ${ }^{5}$, \\ C. M. Berkowitz ${ }^{5}$, and L. T. Molina ${ }^{3,4}$ \\ ${ }^{1}$ Dept. of Civil and Environmental Engineering, Washington State University, Pullman, WA, USA \\ ${ }^{2}$ Dept. of Chemistry and Biochemistry and CIRES, University of Colorado, Boulder, CO, USA \\ ${ }^{3}$ Molina Center for Energy and the Environment (MCE2), La Jolla, CA, USA \\ ${ }^{4}$ Dept. of Earth, Atmospheric, and Planetary Science, Massachusetts Institute of Technology, Cambridge, MA, USA \\ ${ }^{5}$ Battelle Pacific Northwest, P.O.-Box 999, Richland, WA, USA
}

Received: 19 August 2009 - Published in Atmos. Chem. Phys. Discuss.: 23 September 2009

Revised: 6 January 2010 - Accepted: 11 January 2010 - Published: 19 February 2010

\begin{abstract}
A comparison of aromatic hydrocarbon measurements is reported for the CENICA supersite in the district of Iztapalapa during the Mexico City Metropolitan Area field experiment in April 2003 (MCMA 2003). Data from three different measurement methods were compared: a Proton Transfer Reaction Mass Spectrometer (PTR-MS), long path measurements using a UV Differential Optical Absorption Spectrometer (DOAS), and Gas Chromatography-Flame Ionization analysis (GC-FID) of canister samples. The principle focus was on the comparison between PTR-MS and DOAS data. Lab tests established that the PTR-MS and DOAS calibrations were consistent for a suite of aromatic compounds including benzene, toluene, $\mathrm{p}$-xylene, ethylbenzene, 1,2,4-trimethylbenzene, phenol and styrene. The point sampling measurements by the PTR-MS and GC-FID showed good correlations $(r=0.6)$, and were in reasonable agreement for toluene, $\mathrm{C}_{2}$-alkylbenzenes and $\mathrm{C}_{3}$-alkylbenzenes. The PTR-MS benzene data were consistently high, indicating interference from ethylbenzene fragmentation for the $145 \mathrm{Td}$ drift field intensity used in the experiment. Correlations between the open-path data measured at 16-m height over a $860-\mathrm{m}$ path length (retroreflector in $430 \mathrm{~m}$ distance), and the point measurements collected at $37-\mathrm{m}$ sampling height were best for benzene $(r=0.61)$, and reasonably good for toluene, $\mathrm{C}_{2}$-alkylbenzenes, naphthalene, styrene, cresols and phenol $(r>0.5)$. There was good agreement between DOAS and PTR-MS measurements of benzene after correction for the
\end{abstract}

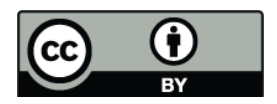

Correspondence to: $\mathrm{B}$. T. Jobson (tjobson@wsu.edu)
PTR-MS ethylbenzene interference. Mixing ratios measured by DOAS were on average a factor of 1.7 times greater than the PTR-MS data for toluene, $\mathrm{C}_{2}$-alkylbenzenes, naphthalene and styrene. The level of agreement for the toluene data displayed a modest dependence on wind direction, establishing that spatial gradients - horizontal, vertical, or both - in toluene mixing ratios were significant, and up to a factor of 2 despite the fact that all measurements were conducted above roof level. Our analysis highlights a potential problem in defining a VOC sampling strategy that is meaningful for the comparison with photochemical transport models: meaningful measurements require a spatial fetch that is comparable to the grid cell size of models, which is typically a few $10 \mathrm{~km}^{2}$. Long-path DOAS measurements inherently average over a larger spatial scale than point measurements. The spatial representativeness can be further increased if observations are conducted outside the surface roughness sublayer, which might require measurements at altitudes as high as $10 \mathrm{~s}$ of metres above roof level.

\section{Introduction}

The Mexico City Metropolitan Area (MCMA-2003) field experiment conducted in the spring of 2003 was an extensive and collaborative scientific effort to update and improve the local emissions inventory, and to gain a better understating of the chemistry and transport processes driving atmospheric pollution in Mexico City (Molina et al., 2007). Mexico City is one of the world's largest cities and has frequent and severe air quality problems owing to the large number of inhabitants

Published by Copernicus Publications on behalf of the European Geosciences Union. 
( $\sim 19$ million), industrial growth (more than 53000 industries) and transport needs ( $\sim 3.5$ million vehicles), in addition to its own topography and meteorology. Mexico City lies in an elevated basin ( $2240 \mathrm{~m}$ above sea level) surrounded by mountain ridges. Its high elevation and relatively low latitude $\left(19^{\circ} 25^{\prime} \mathrm{N}\right)$ lead to intense sunlight promoting photochemical processes that drive the formation of ozone, airborne particulate matter (PM) and other oxidants.

One of the central precursors to both ozone and PM formation are volatile organic compounds (VOCs). The emissions of these compounds are enhanced in Mexico City by the less efficient combustion processes due to the high altitude, as well as the subtropical weather with intense solar radiation that accentuates the evapourative emissions from a variety of sources such as storage and distribution of gasoline, solvent-base cleaning, painting and industrial processes. Sparse vegetation in Mexico City means biogenic VOC emissions are small in comparison to the anthropogenic VOC emissions (Velasco, 2003). During the daytime, the intense and continuous anthropogenic emissions of NO and VOCs, in combination with the high $\mathrm{OH}$ reactivity, generate ozone at rates exceeding $50 \mathrm{ppbv} \mathrm{h}^{-1}$ as early as one hour after sunrise (Shirley et al., 2006). The rapid formation of glyoxal observed after sunrise by Volkamer et al. (2005) during the MCMA-2003 experiment indicates an efficient VOC oxidation process during morning hours, and the high glyoxal level observed until early afternoon reveals a persistently active VOC chemistry during most of the day. Hydrocarbon oxidation products, resulting from these VOC oxidation processes, contribute significantly to the formation of secondary organic aerosols much faster and an order of magnitude larger than expected previously (Volkamer et al., 2006, 2007; Kleinman et al., 2007; Dzepina et al., 2009).

The vast suite of compounds that are present in urban air and their photochemical products makes assessing specific VOC burdens a difficult analytical task. Since no single technique can provide speciated measurements of all the VOCs needed for modelling their impact on urban air photochemistry, different measurement techniques are often used in combination to provide measurements of as many types of species as possible. During the MCMA-2003, VOC measurements were made at different locations inside and outside of Mexico City, including a supersite at the roof top of the Mexican National Center for Environmental Research and Training (CENICA) in the district of Iztapalapa. Four distinct analytical techniques were used to measure VOCs at this site: whole air canister samples with Gas Chromatography/Flame Ionization Detection (GC-FID), on-line chemical ionization using a Proton Transfer Reaction Mass Spectrometer (PTR-MS), continuous real-time detection of olefins using a Fast Isoprene Sensor (FIS) calibrated with a propylene standard, and long path measurements using UV Differential Optical Absorption Spectroscopy (DOAS). The simultaneous use of these techniques provided a wide range of individual VOC measurements with different spatial and temporal scales. Such a situation presents a clear need for a comparison of the measurement techniques to verify that the data can be combined into a single comprehensive data set.

Formal international comparisons between research groups using gas chromatography based systems for the measurement of non-methane hydrocarbons have been reported (Apel et al., 1994, 1999, 2003; Slemer et al., 2002; Volz-Thomas et al., 2002). These studies demonstrated that different calibration standards and analytical procedures could lead to significant differences between laboratories in the analysis of synthetic mixtures and ambient air samples. Analysis problems such as the co-elution of components, losses of volatile $\mathrm{C}_{2}$ components, and adsorptive losses of $\mathrm{C}_{7}-\mathrm{C}_{9}$ components contributed to measurement uncertainty. The best level of agreement was achieved between the most experienced laboratories and was within $\pm 20 \%$ for most compounds in synthetic mixtures and ambient samples (Volz-Thomas et al., 2002). The analysis of oxygenated species is even more problematic (Apel et al., 1998; Fujita et al., 2003) and there have been fewer systematic investigations on the comparison of techniques and data for these species. Kuster et al. (2004) reported on the results of an informal comparison of ambient data from in situ gas chromatography based systems and a PTR-MS instrument that include both non-methane hydrocarbons and oxygenated species. Rogers et al. (2006) compared PTR-MS measurements of aromatic compounds against air samples collected into canisters and analysed by GC-FID and found good agreement for benzene and toluene but significant differences for $\mathrm{C}_{2}$-alkylbenzenes and $\mathrm{C}_{3}$-alkylbenzenes.

There are relatively few reports comparing DOAS based measurements with other VOC measurement techniques. Barrefors (1996) reported a very poor correlation between a commercial DOAS instrument measurement of benzene and GC based measurements for an urban environment $(r=0.18)$. Toluene measurements displayed a much better correlation $(r=0.71)$ but the DOAS measurements were $\sim$ factor of 2 higher. Kim (2004) reported a comparison between a commercial DOAS system and commercial in situ GC-FID system for the measurement of benzene, toluene and the sum of the xylene isomers in a suburban area. In that study, benzene data compared very poorly $(r=0.128)$ and were essentially uncorrelated because mixing ratios were at the detection limit of the DOAS instrument. Regressions between the DOAS and GC data for toluene and xylenes showed significant scatter but were reasonably well correlated, with toluene displaying the best overall correlation and level of agreement.

More recently, Velasco et al. (2007) have reported intercomparison results from a PTR-MS, GC-FID and a commercial DOAS instrument for several days of measurements from an auxiliary monitoring site in Mexico City during the MCMA 2003 field experiment. The comparison showed good agreement, with the exception of benzene measurements by the commercial DOAS, which were greater than the PTR-MS and GC-FID measurements in the early afternoon 
Table 1. Species measured at CENICA for intercomparison.

\begin{tabular}{|c|c|c|}
\hline PTR-MS (ion) & DOAS & Canisters GC-FID \\
\hline benzene (79) & benzene & benzene \\
\hline toluene $(93)$ & toluene & toluene \\
\hline$\Sigma \mathrm{C}_{2}$-alkylbenzenes ${ }^{1}(107)$ & $\Sigma \mathrm{C}_{2}$-alkylbenzenes ${ }^{4}$ & $\Sigma \mathrm{C}_{2}$-alkylbenzenes ${ }^{1,5}$ \\
\hline$\Sigma \mathrm{C}_{3}$-alkylbenzenes ${ }^{2}(121)$ & styrene & $\Sigma \mathrm{C}_{3}$-alkylbenzenes ${ }^{6}$ \\
\hline styrene $(105)$ & phenol & styrene \\
\hline phenol (95) & p-cresol & \\
\hline cresols $^{3}$ (109) & & \\
\hline
\end{tabular}

${ }^{1}$ Includes xylene isomers, ethylbenzene, and benzaldehyde.

2 Includes all $\mathrm{C}_{9} \mathrm{H}_{12}$ isomers.

3 Includes all cresol isomers.

${ }^{4}$ Calculated from measurements of p-xylene, m-xylene, and ethylbenzene (see text).

5 Includes xylene isomers and ethylbenzene.

${ }^{6}$ Includes all $\mathrm{C}_{9} \mathrm{H}_{12}$ isomers except 1,2,3-trimethylbenzene and isopropylbenzene.

when ozone levels were high. The ozone interference can be corrected in the DOAS technique, as was demonstrated in that work from the research grade DOAS data which did not show the high benzene offset during afternoons and showed excellent correlation between benzene, toluene, m-xylene and p-xylene. This paper presents results from a more detailed comparison of PTR-MS, GC-FID and research-grade DOAS measurements of VOCs at the CENICA supersite during MCMA-2003. These techniques measured several aromatic species in common over a period of 4 weeks and provide a much larger dataset for a statistically robust analysis.

\section{Experimental}

\subsection{Sampling location and description}

Measurements were made at the CENICA supersite in Iztapalapa, a suburb of Mexico City with a high population density (more than 12000 inhabitants per $\mathrm{km}^{2}$ ) in a mixed area with residences, light and medium industries, services and commerce. Instruments were housed in an air-conditioned shelter on the roof of the CENICA building. The PTRMS and canisters sampled air from a $25-\mathrm{m}$ walk-up scaffold tower erected on the roof-top. Air from the top of the tower was pulled down through a $5 / 8^{\prime \prime}$ diameter Teflon sampling line at 45 SLPM into the shelter where it was subsampled by a number of instruments including the PTR-MS and canister filling system. These measurements, thus, represent point samples from a 37-m height. The DOAS technique in contrast measures VOCs integrated over a $430 \mathrm{~m}$ air column. The DOAS instrument was also housed in the same shelter and directed its beam at a retro reflector mounted $16-\mathrm{m}$ above the ground on a radio tower $430 \mathrm{~m}$ to the south/southeast. Measurements were made at CENICA from 3 April to 2 May 2003 although the instruments were operating at different times with different sampling frequencies. Table 1 shows the species that were measured in common. Specifics on the individual instruments and measurement methods are described below.

\subsection{PTR-MS}

A PTR-MS instrument (Ionicon Analytik) was used to monitor a number of species. This technique has been described in detail previously (Hansel et al., 1995; deGouw and Warneke, 2007). The technique identifies VOCs by molecular weight and can measure those compounds with a proton affinity greater than that of water. The technique is insensitive to $\mathrm{C}_{2}-\mathrm{C}_{7}$ alkanes, ethene and acetylene, common constituents of urban atmospheres. Given current knowledge of atmospheric VOC composition, primarily accumulated over the last 20 years using chromatography based techniques, there are a number of VOCs that are suited to monitoring by PTRMS because of the uniqueness of their molecular weight and predominance in the atmosphere. A basic issue with the technique is that a number of species dissociate upon protonation and mass fragments can cause interferences at other masses. Also, the technique can not resolve geometric isomers and is subject to isobaric interferences. For example, the xylene isomers $\left(\mathrm{C}_{8} \mathrm{H}_{10}\right)$ can not be distinguished from ethylbenzene $\left(\mathrm{C}_{8} \mathrm{H}_{10}\right)$ and instead the sum of the substituted alkyl benzene species with molecular weight of $106 \mathrm{amu}$ $\left(\mathrm{C}_{2}\right.$-alkylbenzenes $)$ are reported. Benzaldehyde $\left(\mathrm{C}_{7} \mathrm{H}_{6} \mathrm{O}\right)$ is also detected at the same mass and is considered an isobaric interference for the $\mathrm{C}_{2}$-alkylbenzenes determination. These issues require that the PTR-MS technique be verified against GC based measurements in different environments until there is a better understanding of the veracity of the PTR-MS measurement approach for complex organic mixtures such as urban air. The advantages of the PTR-MS are the sampling frequency, the limited sample handling - hence 


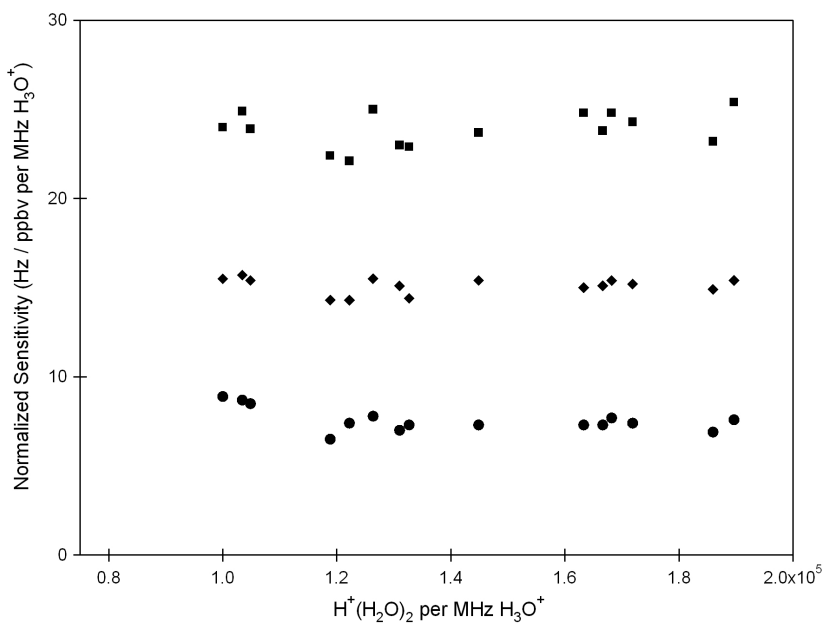

Fig. 1. PTR-MS normalized sensitivities for acetonitrile (squares), acetaldehyde (diamonds), and benzene (circles) versus water cluster count rates. Water cluster count rates were normalized to $\mathrm{MHz}$ $\mathrm{H}_{3} \mathrm{O}^{+}$. No water vapour dependence was observed.

the ability to measure oxygenated species otherwise difficult to determine with canister based sampling approaches - and the relative ease and cost effectiveness of data workup. During MCMA 2003, the PTR-MS was operated using a 2.1 mbar ion drift pressure and a drift field intensity of $145 \mathrm{Td}$. Twenty-two organic ions were monitored during the study. Table 1 shows a partial list of the ions monitored and the species represented by these ions for those species measured in common by the DOAS and GC-FID techniques. Laboratory measurements of the vapour from pure compounds confirm that phenol and cresols did not fragment in the PTR-MS and, thus, could be quantified using their $\mathrm{M}+1$ ion abundance.

The PTR-MS sensitivity was determined with a multicomponent compressed gas standard from Apel-Reimer Environmental (Denver, USA) containing hydrocarbons (benzene, toluene, p-xylene, 1,2,4-trimethylbenzene, acetonitrile, isoprene and a-pinene), and oxygenated species (methanol, acetaldehyde, acetone, 2-butanone, methacrolein and methylvinylketone). The standard had a stated accuracy of $\pm 2 \%$ for hydrocarbons and $\pm 5 \%$ for oxygenated species. The gas standard was dynamically diluted with humid zero air that was continuously produced by passing ambient air through a heated tube $\left(300^{\circ} \mathrm{C}\right)$ packed with platinum pellets (1\% weight on alumina spheres). Multipoint calibrations were performed every couple of days. The pxylene and 1,2,4-trimethylbenzene sensitivities were used to represent the average group sensitivity for the sum of $\mathrm{C}_{2}$ alkylbenzenes and $\mathrm{C}_{3}$-alkylbenzenes, respectively.

Instrument normalized sensitivities ( $\mathrm{Hz} / \mathrm{ppbv}$ per $\mathrm{MHz}$ $\mathrm{H}_{3} \mathrm{O}^{+}$) were not dependent on water vapour concentrations. As an example, Fig. 1 displays normalized sensitivities for acetonitrile, acetaldehyde and benzene versus $\mathrm{H}^{+}\left(\mathrm{H}_{2} \mathrm{O}\right)_{2}$ count rates normalized to $\mathrm{MHz} \mathrm{H}_{3} \mathrm{O}^{+}$. Depending on the operating conditions, the PTR-MS instrument can display a humidity dependent sensitivity because $\mathrm{H}^{+}\left(\mathrm{H}_{2} \mathrm{O}\right)_{2}$ can act as a reagent ion. For this particular PTR-MS instrument there was no discernable humidity dependence for the $145 \mathrm{Td}$ and 2.1 mbar drift pressure operating condition. Interestingly, for similar drift tube conditions (145 Td, $1.9 \mathrm{mbar}$ ), Rogers et al. (2006) reported significant humidity dependent sensitivities over a similar humidity range. This difference in PTR-MS instrument behaviour reinforces the need to calibrate PTR-MS instruments across a range of ambient humidity levels to document the humidity dependence.

The phenol sensitivity was determined in the laboratory using a permeation tube, $567 \mathrm{ng} / \mathrm{min} \pm 2 \%$ (VICI Metronics) and referenced against toluene sensitivity determined from the compressed gas standard. Flows from the permeation device and the compressed gas standard were mixed and then dynamically diluted with humid zero air ( $\sim 6 \% \mathrm{RH}$ at $22^{\circ} \mathrm{C}$ ). The measured phenol-to-toluene sensitivity ratio was determined to be 1.3 and this ratio was used for field calibrations. This measured sensitivity ratio was comparable to the calculated sensitivity ratio of 1.2 determined from the ratio of their collisional rate coefficients with $\mathrm{H}_{3} \mathrm{O}^{+}$(Su and Chesnavich, 1982; Su 1989; Zhao and Zhang, 2004). Given their small difference in mass and, hence, small difference in ion transmission efficiency, the difference in sensitivity between toluene and phenol were attributed to differences in reaction kinetics. We observed that phenol displayed a humidity dependent sensitivity under these drift conditions. Dry zero air calibrations performed in the lab yielded sensitivities $\sim 25 \%$ lower than the humid air calibrations.

Cresol sensitivity was referenced to as the sensitivity of p-xylene. The calculated collisional rate coefficients for the cresol isomers average $10 \%$ more than that of p-xylene. Styrene sensitivities were assumed to be equal to those of p-xylene since their calculated collisional rate coefficients and ion masses were similar. Likewise, naphthalene sensitivity was assumed to be equivalent to that of $1,2,4-$ trimethylbenzene since the rate coefficients and ion masses were similar.

Partial fragmentation of mono-alkyl aromatics such as ethylbenzene occurs under the ion drift conditions used here. Mass scans of ethylbenzene show a dominant $\mathrm{M}+1$ ion but also a significant ion at $m / z=79(40 \%)$. This fragmentation produces a positive artifact for PTR-MS benzene measurements and causes the PTR-MS to underestimate $\mathrm{C}_{2}$ benzenes. Rogers et al. (2006) provided an algorithm to correct the PTR-MS benzene measurements due to fragmentation of ethylbenzene and n-propylbenzene. The magnitude of this interference can be calculated from known abundances of $\mathrm{C}_{2}$-alkylbenzene and $\mathrm{C}_{3}$-alkylbenzenes isomers. The GC-FID measurements at CENICA, other sites in Mexico City (Rogers et al., 2006), and in US urban environments (e.g. Jobson et al., 2004) indicate that ethylbenzene comprises of about $20 \%$ of the $\mathrm{C}_{2}$-alkylbenzenes abundance 
and n-propylbenzene about $7 \%$ of the $\mathrm{C}_{3}$-alkylbenzene abundance. Given the fragmentation of ethylbenzene and its relative abundance, the PTR-MS measurements underestimated $\mathrm{C}_{2}$-alkylbenzenes abundance by $\sim 8 \%$. Using the Rogers et al. (2006) algorithm and the molar abundance of $\mathrm{C}_{2}$ alkylbenzene and $\mathrm{C}_{3}$-alkylbenzenes measured at CENNICA, we estimate that the PTR-MS benzene measurements were over estimated by $\sim 16 \%$, primarily due to fragmentation of ethylbenzene.

The PTR-MS was operated in two different measurement modes reflecting differences in the number of ions measured and the dwell times used. In the middle third of the experiment, the instrument was used in a VOC flux study (Velasco et al., 2004). During this period (10 April-16 April), only four analyte ions were monitored $(33,59,93,107)$ at a high time resolution $(0.2 \mathrm{~s}$ dwell time). For the remainder of the study (4 April-9 April, 22 April-1 May) single ion monitoring was done on about 12 masses with dwell times ranging from 2 to $5 \mathrm{~s}$, resulting in about 1 min sample intervals. A turbopump failure occurred midway through the study and there is no data from 17 April to 21 April.

Backgrounds for the PTR-MS were performed automatically by sampling air from the zero air generator. Ambient data were well above detection limits for most species. In the ambient mode of operation, detection limits were estimated to be $\sim 100 \mathrm{pptv}$ for benzene, toluene, $\mathrm{C}_{2}$-alkylbenzenes and $\mathrm{C}_{3}$-alkylbenzenes. Detection limits for phenol, cresols, styrene and naphthalene were estimated from the signal-tonoise ratio of the raw data during stable clean air periods. For phenol, cresols and styrene the detection limit was approximately $50 \mathrm{pptv}$, while for naphthalene it was approximately $60 \mathrm{pptv}$. At these mixing ratios the $1 \sigma$ variation about the mean was $30 \%$. The ambient data for these species was occasionally near the detection limit, especially for cresols.

\subsection{DOAS}

Two long path Differential Optical Absorption Spectroscopy (LP-DOAS) instruments were installed on the rooftop of the CENICA building. The DOAS technique has been described elsewhere (Platt, 1994). In brief, light from a broadband UV/vis lightsource (Xe-short arc lamp) is projected into the open atmosphere onto a distant array of retro reflectors, which folds the lightpath back into the instrument where spectra are recorded using a Czerny-Turner type spectrometer coupled to a 1024-element PDA detector. Only data from DOAS\#1 will be presented here; DOAS\#2 is described elsewhere (Volkamer et al., 2005). Both instruments were operated by the CU Boulder/MIT team. The light path of DOAS\#1 was directed towards a telephone antenna tower in a south-easterly direction at an average height of $16 \mathrm{~m}$ with a $430 \mathrm{~m}$ path length (total $860 \mathrm{~m}$ ). DOAS\#1 measured $\mathrm{O}_{3}, \mathrm{NO}_{2}, \mathrm{SO}_{2}, \mathrm{HONO}, \mathrm{HCHO}$, benzene, toluene, m-xylene, p-xylene, mono-substituted alkylbenzenes $\left(\mathrm{C}_{2}\right.$ and higher), phenol, p-cresol and benzaldehyde by observing the unique specific narrow-band $(<5 \mathrm{~nm})$ absorption structures of these molecules. Also naphthalene and styrene were measured for the first time with DOAS in the atmosphere (Flores et al., 2004). Spectra were recorded by sequentially observing 40$\mathrm{nm}$ wide wavelength intervals in the wavelength range between $240 \mathrm{~nm}$ and $375 \mathrm{~nm}$ at $0.2 \mathrm{~nm}$ FWHM spectral resolution. The time resolution of recording a full cycle of spectra varied between $30 \mathrm{~s}$ and $4 \mathrm{~min}$, depending on the abundance of UV-light absorbing ozone. Reference spectra of aromatic compounds were recorded by introducing quartzcuvettes filled with vapour into the light beam, and these spectra were calibrated to absorption cross-section spectra taken from the literature (Etzkorn et al., 1999). Absorptions of atmospheric oxygen were eliminated using the interpolation approach of Volkamer et al. (1998). In brief, saturation of molecular absorption lines of oxygen in the Herzberg IIII bands were modelled in high-resolution using line parameters from (Fally et al. (2000), Jenouvrier et al. (1999) and Merienne et al. (2000, 2001) and oxygen column densities of $3.7 \times 10^{17}$ molecules $\mathrm{cm}^{-2}$ and $4.1 \times 10^{17}$ molecules $\mathrm{cm}^{-2}$ to bracket the effect of density variations on oxygen column densities. The collision induced absorption of oxygen in the Wulf bands was fitted using the literature spectra from (Bernath et al. (1998). For ozone, temperature dependent absorption cross-sections (Bass and Paur, 1981) for $293 \mathrm{~K}$ and $313 \mathrm{~K}$ were convoluted to match the spectral resolution of the instruments, and fitted simultaneously with other trace-gas reference spectra and a fifth order polynomial high-pass filter to account for broadband molecule and aerosol extinction using nonlinear least-squares fitting routines (Stutz et al., 1996; Fayt et al., 2001). The mean detection limits were: $1.3 \mathrm{ppbv}$ $\left(\mathrm{O}_{3}\right), 1.5 \mathrm{ppbv}\left(\mathrm{NO}_{2}\right), 0.26 \mathrm{ppbv}\left(\mathrm{SO}_{2}\right), 0.5 \mathrm{ppbv}$ (HONO), $5 \mathrm{ppbv}$ (HCHO), $1 \mathrm{ppbv}$ (benzene, toluene, m-xylene), $0.3 \mathrm{ppbv}$ (p-xylene), $1.8 \mathrm{ppbv}$ (ethylbenzene-equivalents), $0.5 \mathrm{ppbv}$ (styrene), $0.06 \mathrm{ppbv}$ (phenol, p-cresol), $0.2 \mathrm{ppbv}$ (benzaldehyde), $0.08 \mathrm{ppbv}$ (naphthalene).

While DOAS measurements allow for the selective detection of xylene-isomers, only m- and p-xylene were sufficiently abundant to be detected. Since the PTR-MS is not isomer-specific, xylene isomers and ethylbenzene were summed to calculate total $\mathrm{C}_{2}$-alkylbenzenes, accounting for the fact that other n-alkyl benzenes and ethylbenzene have similar UV absorption features (Axelsson et al., 1995). A formula was derived to estimate the sum of the $C_{2}$ benzenes based on the abundance of the measured isomers and the apparent correction required for DOAS measurements of ethylbenzene to bring them into agreement with the GC-FID analysis of canisters collected at CENICA. The relationship is valid for fresh emissions.

$\Sigma \mathrm{C}_{2}$-alkylbenzenes

$=1.4^{*}(\mathrm{~m}$-xylene $+\mathrm{p}$-xylene $)+0.21^{*}$ ethylbenzene 

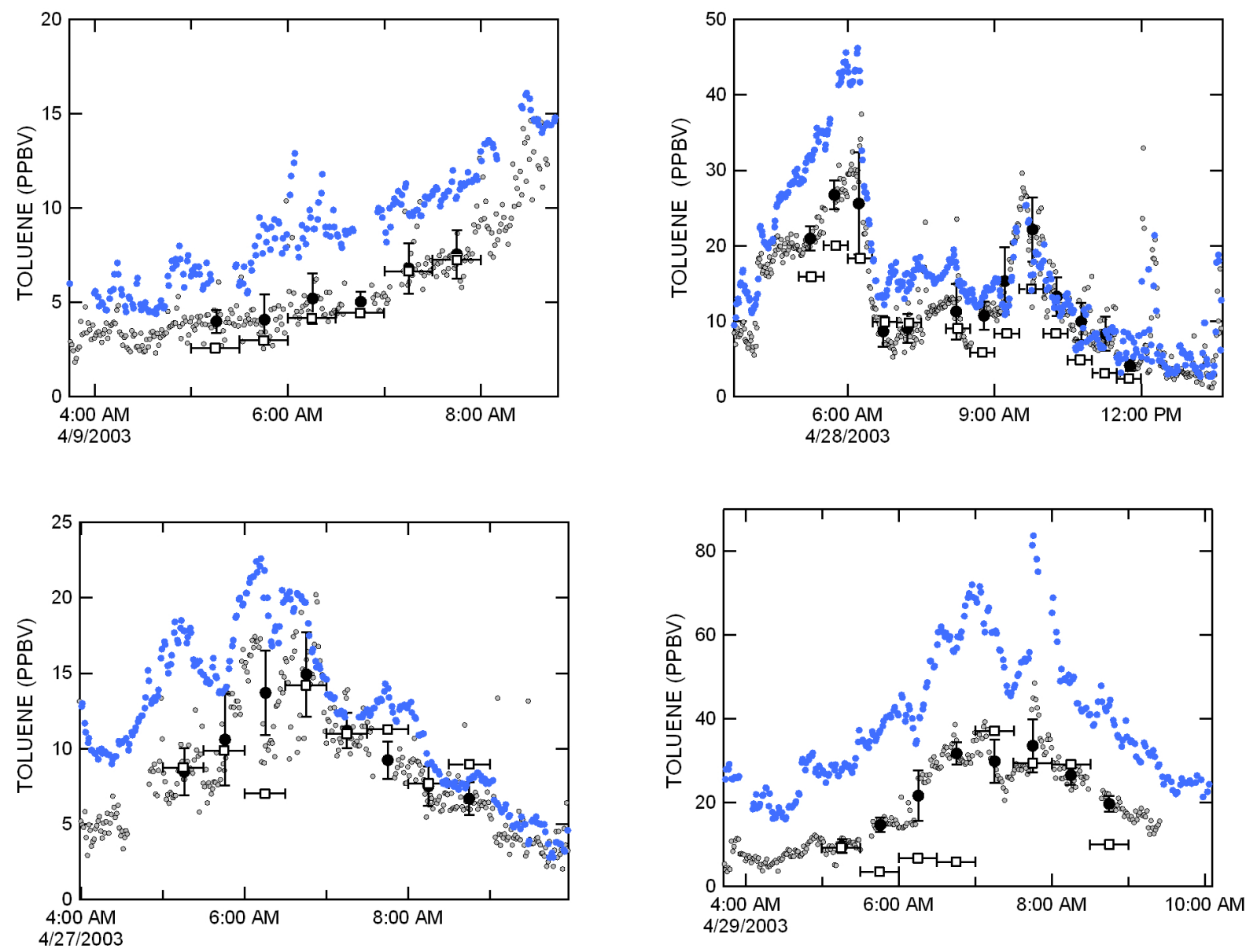

Fig. 2. Time series of toluene measurements made by the PTR-MS (grey circles), DOAS (blue circles), canister GC-FID (open squares) and PTR-MS data averaged over the canister fill time (filled circles). Error bars on the canister data represent the fill time range.

\subsection{Canister Analysis by GC-FID}

Forty-four samples were collected in electro-polished stainless-steel canisters. The canisters were filled over a $30 \mathrm{~min}$ period with an automated sampler (Xon Tech, Inc. model 910PC). Approximately $60 \%$ of the samples were collected between 06h00 and 09h00 LT (local time) when VOC concentrations were highest due to roadway traffic emissions. The remaining samples were collected during the rest of the morning and early afternoon. All samples were analysed on site within $24 \mathrm{~h}$ of sampling using an Agilent 6890 gas chromatograph with flame ionization detection. Air samples were cryogenically preconcentrated on a glass bead packed trap and analysed on a 30-m DB-1 column $(0.32 \mathrm{~mm}$ id and $1 \mathrm{um}$ phase thickness). The detector response was calibrated with a NIST traceable standard of 2,2-dimethylbutane (stated accuracy $\pm 10 \%$ ). The detection limit was calculated to be $20 \mathrm{pptC}$.

\section{Results and discussion}

\subsection{PTR-MS versus GC-FID}

There were a total of 43 canisters that were collected when the PTR-MS was operating. Canisters were filled on 9, 13, 14, 27, 28 and 29 April. Only toluene and $C_{2}$-alkylbenzenes data from the PTR-MS were available for 13 and 14 April. The PTR-MS data were averaged over the $1 / 2 \mathrm{~h}$ canister fill times. Figure 1 shows the toluene time series for four of these days to illustrate the temporal variability and level of agreement between the two measurements. Occasionally there were large changes in concentration over the canister fill period, reflected by a large standard deviation in the PTR-MS averaged data.

A number of canister data from 28 and 29 April had low values for several species. This is clearly evident in the toluene data of Fig. 2 for the 4 samples collected on 29 April. Even larger deviations were noted for $\mathrm{C}_{2}$-alkylbenzenes and $\mathrm{C}_{3}$-alkylbenzenes. To evaluate this discrepancy, a comparison of datasets was performed by comparing hydrocarbon to 
Table 2. Linear regressions fit parameters to GC-FID data.

\begin{tabular}{|c|c|c|c|c|}
\hline Species & Slope & Intercept (ppbv) & $r$ & \# Data points \\
\hline \multicolumn{5}{|c|}{ PTR-MS regressions } \\
\hline benzene & $0.95 \pm 0.06$ & $1.1 \pm 0.13$ & 0.646 & 35 \\
\hline toluene & $1.06 \pm 0.06$ & $0.46 \pm 0.34$ & 0.657 & 31 \\
\hline$\Sigma \mathrm{C}_{2}$-alkylbenzenes & $1.10 \pm 0.07$ & $-0.20 \pm 0.23$ & 0.614 & 31 \\
\hline$\Sigma \mathrm{C}_{3}$-alkylbenzenes & $1.17 \pm 0.07$ & $0.09 \pm 0.15$ & 0.631 & 23 \\
\hline \multicolumn{5}{|c|}{ DOAS regressions } \\
\hline benzene & $0.84 \pm 0.05$ & $0.84 \pm 0.09$ & 0.478 & 36 \\
\hline toluene & $0.98 \pm 0.04$ & $2.20 \pm 0.22$ & 0.364 & 33 \\
\hline$\Sigma \mathrm{C}_{2}$-alkylbenzenes & $1.39 \pm 0.07$ & $2.04 \pm 0.32$ & 0.344 & 29 \\
\hline
\end{tabular}

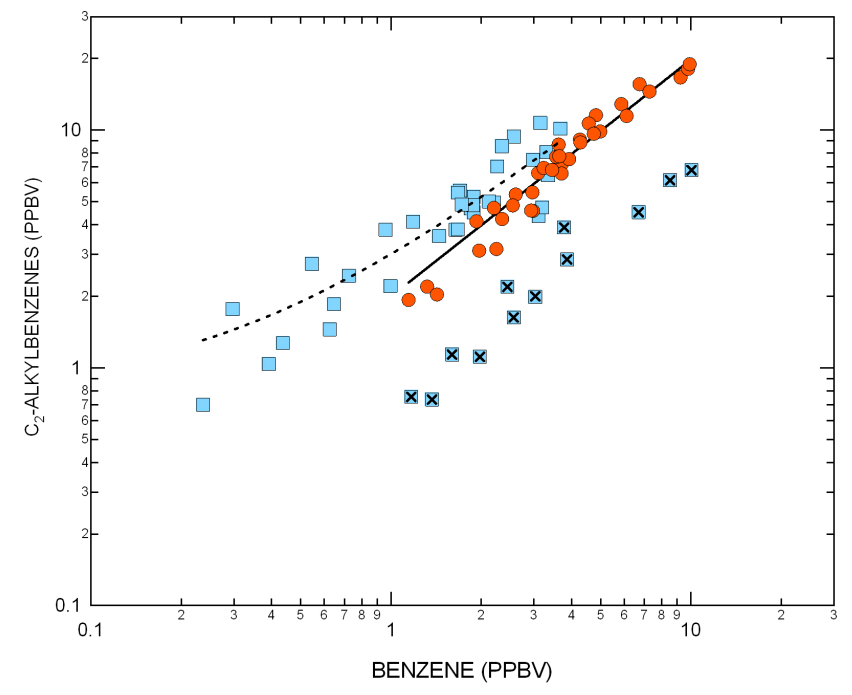

Fig. 3. $\mathrm{C}_{2}$-alkylbenzenes versus benzene relationship for PTR-MS data (circles) and GC-FID data (squares) illustrating the outlying nature of several canister samples collected on 28 April and 29 April indicated by crossed square symbols. The solid line is the linear regression fit through the PTR-MS data and the dashed lines is the linear regression fits through the GC-FID data excluding the 28 April and 29 April outliers.

benzene correlations. This is illustrated in Fig. 3 for the $\mathrm{C}_{2}$ alkylbenzene data. One would anticipate a strong correlation between aromatic hydrocarbons and benzene mixing ratios in urban areas since these species have similar sources. An analysis of hydrocarbon ratios can be an effective means of screening data for quality (Parrish et al., 1998). As shown in Fig. 3, the averaged PTR-MS data defined a compact linear relationship with a slope of $1.98 \pm 0.7$ and Pearson correlation coefficient $r=0.978$. The GC-FID data also defined a linear trend though several samples collected on 28 and 29 April, but displayed much lower $\mathrm{C}_{2}$-alkylbenzene to benzene ratios than the rest of the data. These same canister samples also yielded anomalously low $\mathrm{C}_{3}$-alkylbenzene to benzene ratios. It appears that heavier hydrocarbons $\left(\mathrm{C}_{7}-\mathrm{C}_{9}\right)$ were lost in the collection or analysis for these samples. The cause of this was not clear. These data were labelled as "outliers" and excluded from the comparison.

Plots of averaged PTR-MS data versus canister/GC-FID data are shown in Fig. 4. The data were fit with a monovariate linear regression weighted by the standard deviation of the PTR-MS data. The results of these fits are shown in Table 2. Most of the data fell within 20\% of the 1:1 line and the slopes of the regression fits were close to unity. Regression through the benzene data yielded a significant positive intercept, suggesting the possibility of positive interferences for PTR-MS benzene data. As noted earlier, this mass experiences positive interference from fragmenting alkyl aromatics, notably ethylbenzene. Fragmenting ethylbenzene and propylbenzene would cause PTR-MS benzene data to be overestimated by $\sim 16 \%$, an error that would be reflected in the slope. The intercept, however, indicates the presence of a systematic bias in one of the techniques. The PTR-MS to GC-FID benzene ratio was 1.1 at the highest benzene ratios ( $>6 \mathrm{ppbv}$ ), but displayed more variability and a tendency to increase at lower mixing ratios $(<4 \mathrm{ppbv})$. For the lower mixing ratios, the average PTR-MS to GC-FID ratio was $1.8 \pm 0.6$. The reason for this large and variable difference could not be identified. The results for styrene are not shown as there was a poor correlation between the datasets, due likely to a co-elution problem on the DB-1 column. Rogers et al. (2006) have shown a similar comparison between PTR-MS and GC-FID measurements of benzene, toluene, $\mathrm{C}_{2}$-alkybenzenes and $\mathrm{C}_{3}$ alkylbenzenes made at auxiliary ground sites in Mexico City during MCMA 2003. Their data displayed less scatter and showed better agreement for benzene and toluene than the CENICA data, but the PTR-MS data for $\mathrm{C}_{2}$-alkylbenzenes and $\mathrm{C}_{3}$-alkylbenzenes was significantly greater than GC-FID data (by $31 \%$ and $52 \%$, respectively). 

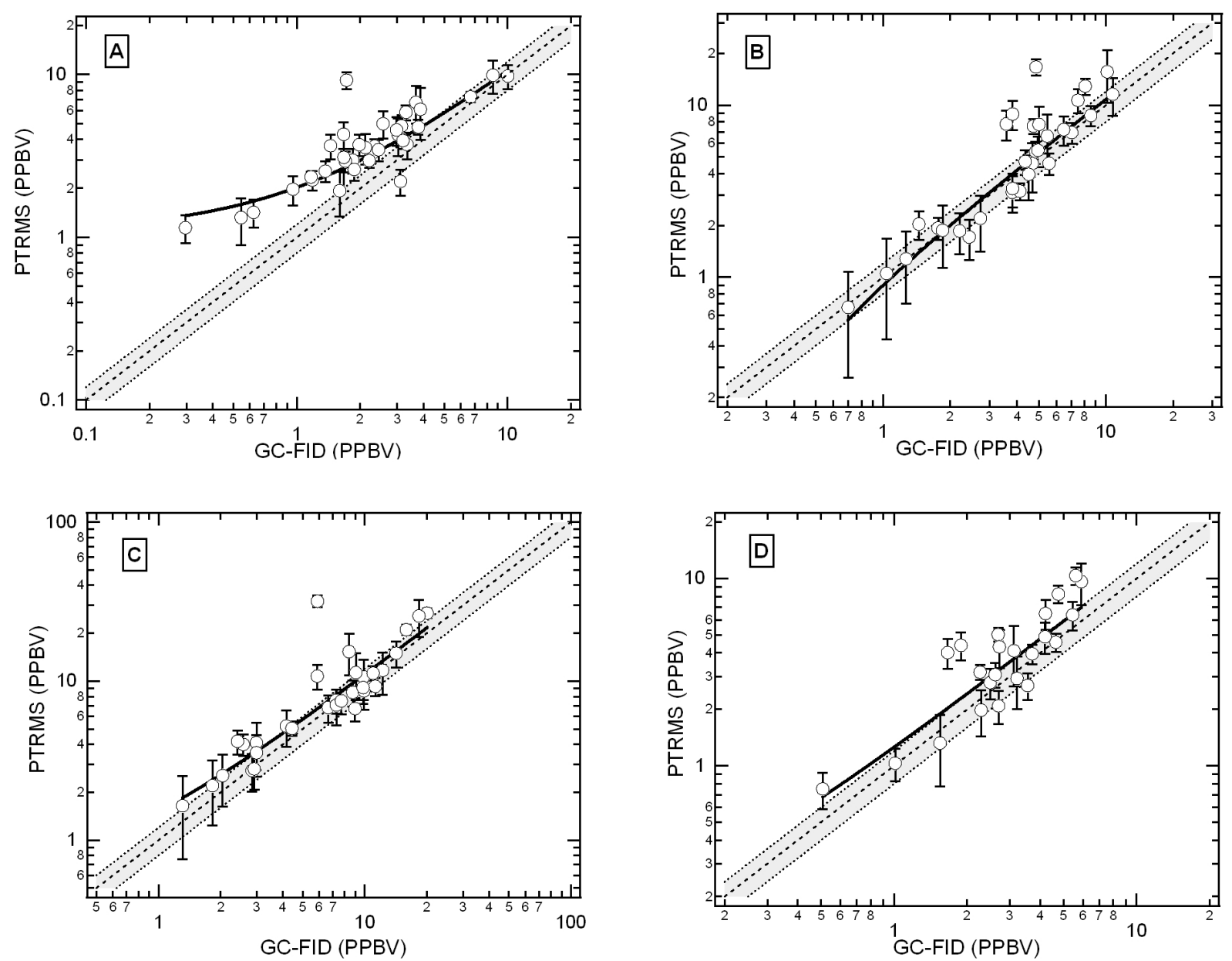

Fig. 4. PTR-MS versus GC-FID: (a) benzene (b) $\mathrm{C}_{2}$-alkylbenzenes (c) toluene (d) $\mathrm{C}_{3}$-alkylbenzene isomers. Regression fits are indicated by the solid black line. Dashed line is the $1: 1$ line bounded by $\pm 20 \%$ range (grey shading).

\subsection{DOAS versus GC-FID}

The comparison between the DOAS data averaged over the $1 / 2 \mathrm{~h}$ canister collection times and the GC-FID analysis of the canisters are displayed in Fig. 5. The level of agreement for benzene was reasonable with most data scattered about the 1:1 line. A linear regression through the data, excluding data below the 1 ppbv DOAS detection limit, weighted by the standard deviation of the DOAS data, yielded a slope of $0.84 \pm 0.05$ and an intercept of $0.84 \pm 0.09$, though it is noted that this intercept is compatible with zero within the DOAS detection sensitivity. The average DOAS to GC-FID benzene ratio was $1.4 \pm 0.5$. The DOAS toluene and $\mathrm{C}_{2}$-alkylbenzene data were frequently much higher than GC-FID measurements and overall displayed a greater variability than the PTR-MS versus GC-FID plots. This may indicate a general problem in comparing point sampling to long path sampling for reactive hydrocarbons because of significant spatial gradients in urban areas. This point will be explored below. The regression fits to the data are given in Table 2 . The average
DOAS to GC-FID ratio for toluene was $2.0 \pm 1$.6. For $\mathrm{C}_{2}$ alkylbenzenes the average ratio was $2.4 \pm 1.4$. We note that there was a poor level of agreement for the styrene data with most of the DOAS data below detection limits for these sampling periods.

\subsection{PTR-MS versus DOAS}

\subsubsection{Lab tests of synthetic mixtures}

The potential level of agreement between the PTR-MS and DOAS measurements for aromatics was assessed based on the analysis of trace gas concentrations in both single and multicomponent mixtures prepared in the lab. In these experiments, a glass bulb was evacuated and filled to a known pressure with the vapour from a vial containing the pure compound $(>98 \%)$. The bulb was back filled with He to a 1000 torr pressure. A $10 \mathrm{~cm}$ cuevette was filled from the bulb and the UV/Vis absorbance spectrum recorded on a Shimadzu UV-2501PC Ultraviolet-Visible spectrometer. The 

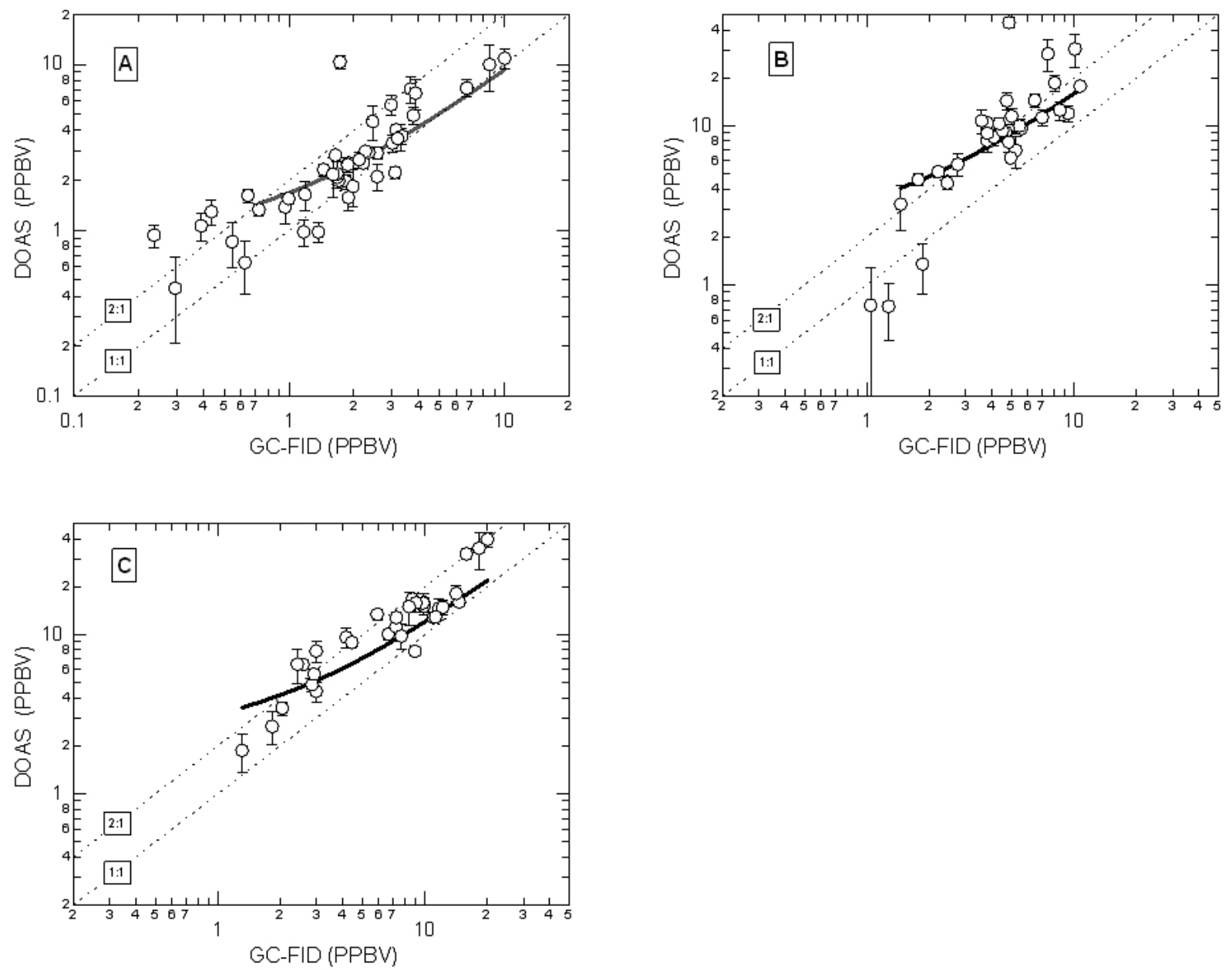

Fig. 5. DOAS versus GC-FID: (a) benzene (b) $\mathrm{C}_{2}$-alkylbenzenes (c) toluene. Regression fit to the data is given by the solid black line. Dashed lines show slopes of $2: 1$ or $1: 1$, as noted.

bulb concentration was calculated using the DOAS technique from the recorded spectrum. Immediately after recording the UV/Vis spectrum, the bulb mixture was diluted with dry air in a dynamic flow system and the output measured by the PTR-MS. Dilution by a factor of 10000 or more was necessary to bring the high concentration bulb mixture to within the analytical range of the PTR-MS instrument. Flow rates through the mass flowmeters were calibrated against a primary standard with an accuracy of $0.25 \%$ (DryCal ML-500, BIOS International Corp). The experimental set-up is shown in Fig. 6. A least three levels of dilution were performed for each compound spanning about a factor of 10 range in mixing ratios. The PTR-MS was calibrated with the same multicomponent VOC standard and the procedure used in the field calibrations. For these tests, the standard was diluted in dry zero to match the matrix of the bulb diluent. The phenol sensitivity was determined with a permeation device diluted with dry zero air. A plot of measured mixing ratios by PTR-MS versus calculated DOAS mixing ratios was made for each compound as shown in Fig. 7. The
DOAS values were calculated from the measured concentrations in the bulb multiplied by the respective dilution factor. Naphthalene and phenol required a long time before transfer lines became equilibrated and a stable PTR-MS signal was observed. With the exception of naphthalene, the PTR-MS measurements agreed with the UV/Vis calculated concentrations for dry conditions within the experimental uncertainty of the respective determinations. The regression results are shown in Table 3. It was concluded that the calibrations of the two systems were consistent. Naphthalene was difficult to work with due to its low vapour pressure. The PTR-MS observed higher naphthalene concentrations than the DOAS calculations. This may have been due to loss of naphthalene to the UV/Vis cuevette during sample transfer.

While the lab experiment with test mixtures demonstrated consistency in the calibrations of the two techniques, it does not identify potential problems with ambient sampling where there may be interferences. This is a particular concern with the PTR-MS measurements which can suffer mass interferences from fragmentation of larger organics 


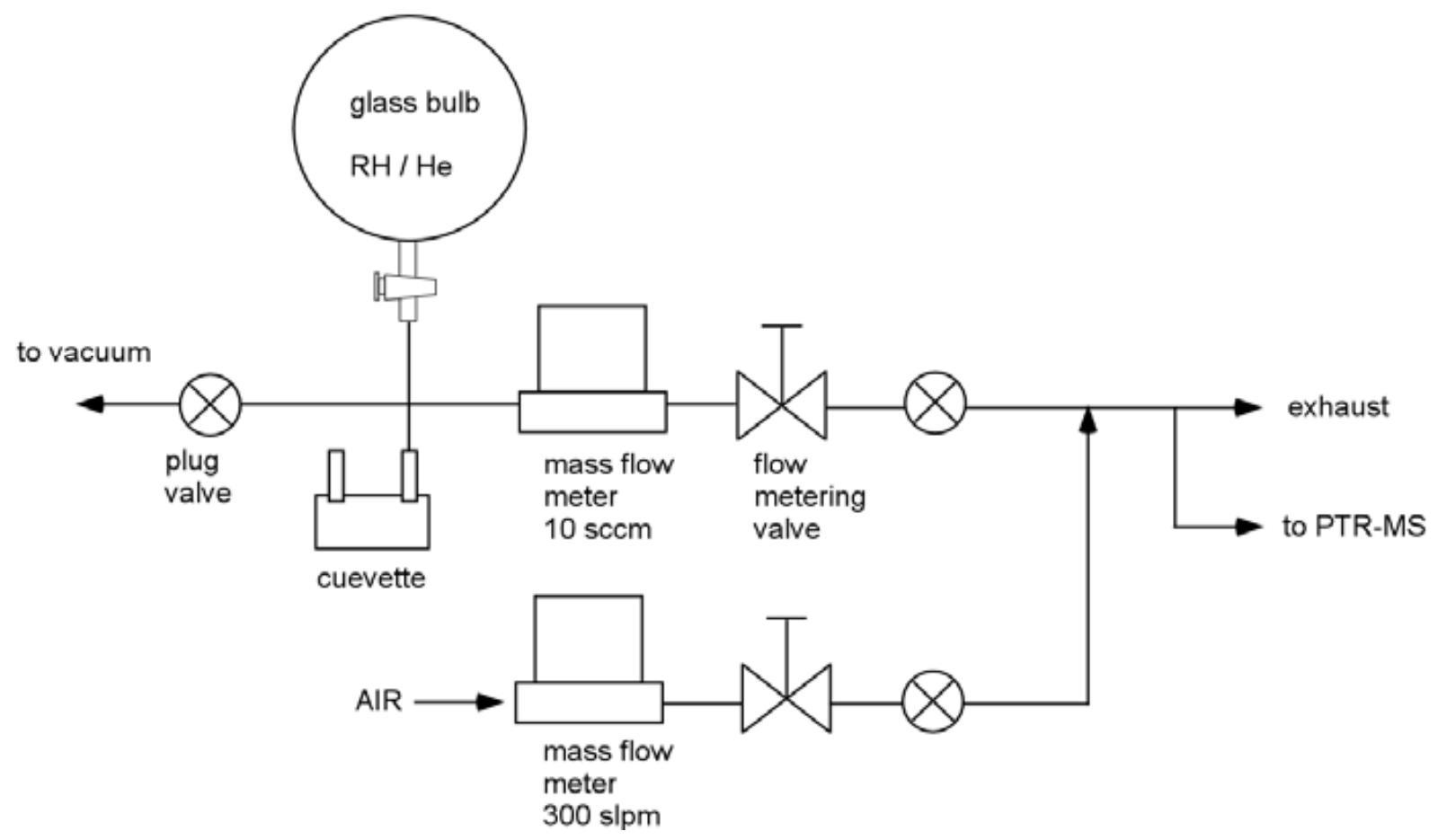

Fig. 6. Schematic of the dynamic dilution system used to dilute the glass bulb mixtures for measurement by the PTR-MS instrument. A quartz cuevette could be filled from the glass bulb to determine aromatic concentration in the bulb by UV/Vis absorption spectrometry. Lines were heat traced from the bulb to the PTR-MS.

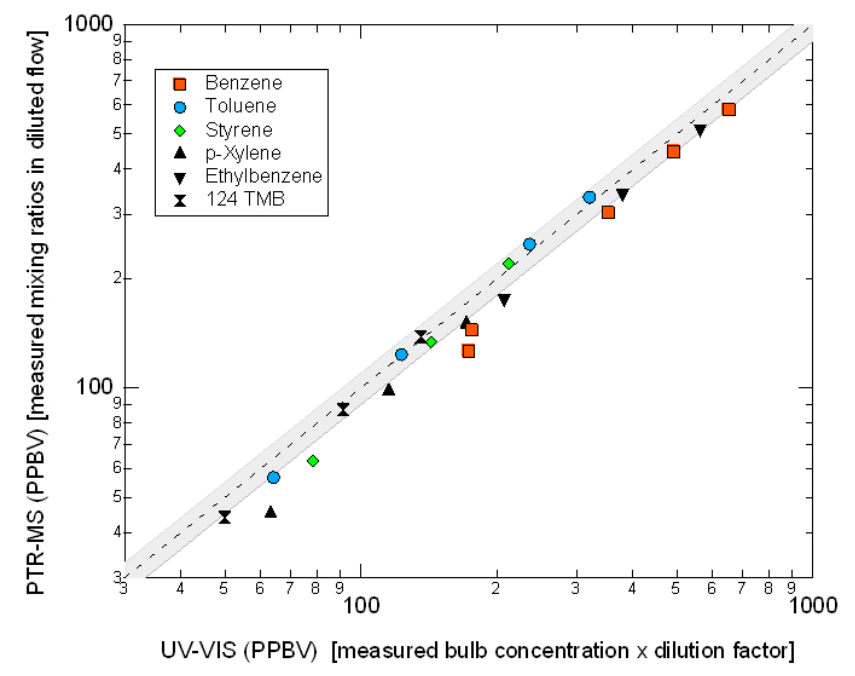

Fig. 7. Results from sampling prepared gas mixtures of aromatic species to evaluate the respective calibrations of the PTR-MS and DOAS instruments. The dashed line is the 1:1 line bounded by $\pm 10 \%$ range (grey shading).

and we note the fidelity of PTR-MS measurements of phenol, cresols, naphthalene and styrene in urban atmospheres has not been demonstrated. One general potential problem for these species could be reactions between $\mathrm{O}_{2}^{+}$and higher concentration organics producing fragment ions at
Table 3. PTR-MS versus DOAS regressions fit parameters from prepared mixtures.

\begin{tabular}{lclr}
\hline Species & Slope & $\begin{array}{l}\text { Intercept } \\
\text { (ppbv) }\end{array}$ & $\begin{array}{r}\text { Data Range } \\
\text { UV/VIS (ppbv) }\end{array}$ \\
\hline benzene & $0.95 \pm 0.02$ & $-29 \pm 9.4$ & $173-651$ \\
toluene & $1.09 \pm 0.02$ & $-11 \pm 3.5$ & $64-321$ \\
phenol & $0.96 \pm 0.04$ & $-6.1 \pm 3$ & $15-71$ \\
p-xylene & $0.97 \pm 0.02$ & $-16 \pm 3$ & $63-171$ \\
styrene & $1.16 \pm 0.08$ & $-29 \pm 10$ & $78-212$ \\
ethylbenzene & $0.96 \pm 0.01$ & $-23 \pm 3$ & $207-563$ \\
$\begin{array}{l}\text { 1,2,4-trimethyl- } \\
\text { benzene }\end{array}$ & $1.08 \pm 0.03$ & $-12 \pm 3$ & $50-135$ \\
naphthalene & $1.73 \pm 0.04$ & $-15 \pm 3$ & $18-95$ \\
\hline
\end{tabular}

these masses. For example, Spanel and Smith (1998) have shown that $\mathrm{O}_{2}^{+}$reactions with trimethylbenzenes produce $\mathrm{C}_{8} \mathrm{H}_{9}^{+}$ions in $5-15 \%$ product yields which would be a mass interference for styrene at $m / z=105$. For a $15 \%$ product yield and an $\mathrm{O}_{2}^{+}$ion abundance in our system of $1.5 \%$, we calculate that the $\mathrm{O}_{2}^{+}+$trimethylbenzene reactions yield an ion signal at $m / z=105$ that is only $0.2 \%$ of the $m / z=121$ ion signal. This reaction was not a significant interference for styrene. 

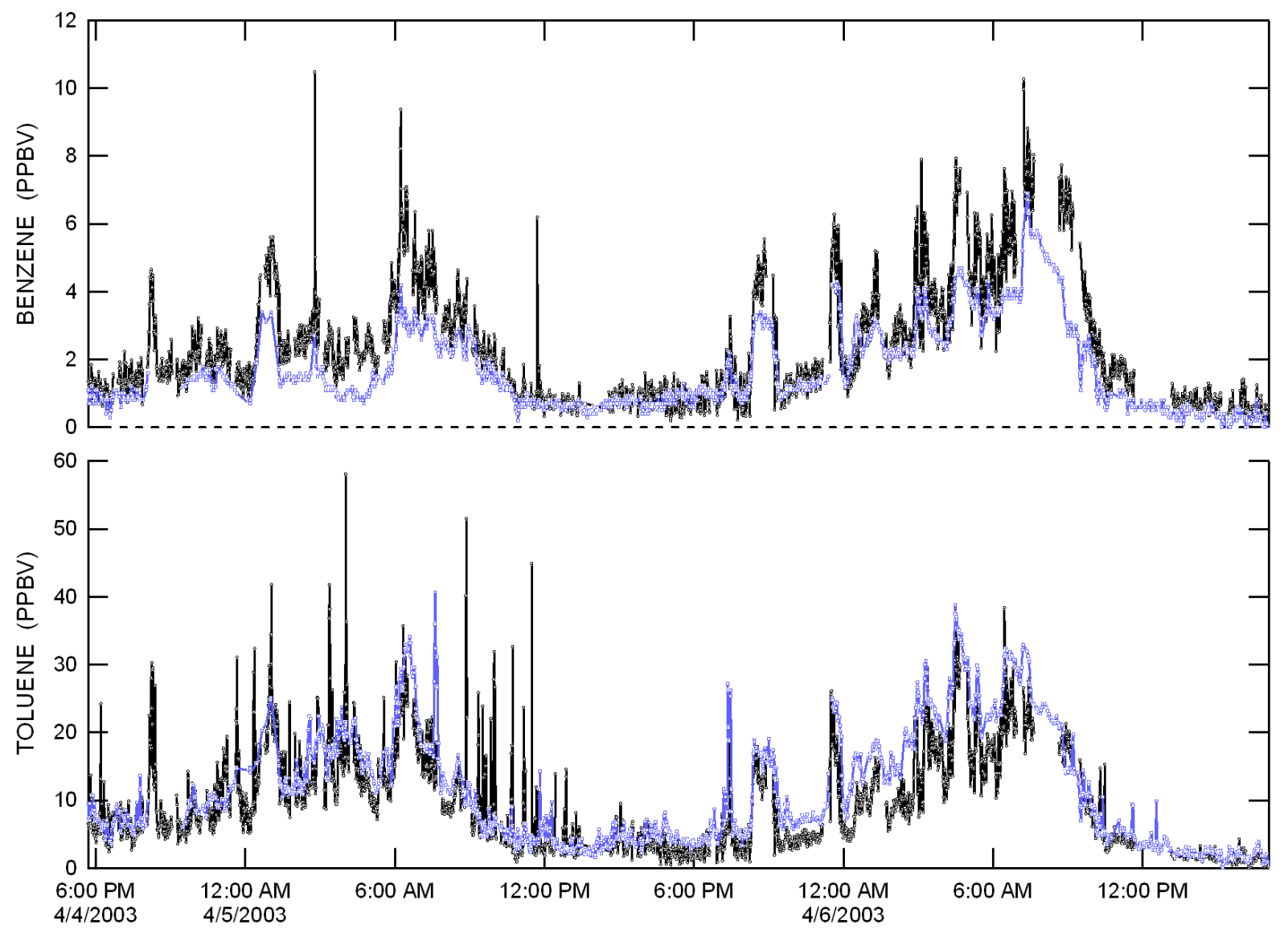

Fig. 8. Time series of PTR-MS (black trace) and DOAS based measurements (blue trace) of benzene (upper panel) and toluene (lower panel). The data show remarkable agreement on relatively small time scales.

\subsubsection{PTR-MS versus DOAS regressions}

The DOAS and PTR-MS measured VOCs on different temporal and spatial scales. While time averaging allows data, collected at different frequencies, to be compared, it is not at all clear how well a point measurement will agree with a long path measurement in an urban area, in particular for reactive hydrocarbons emitted from multiple sources. The issue is the potential for concentration gradients between the average concentration along the DOAS beam and the highly localized measurements by PTR-MS. Figure 8 illustrates the level of agreement for a two day period for benzene and toluene. Overall the DOAS and PTR-MS follow each other remarkably well. Occasionally short-term high concentration "plumes" appear in the PTR-MS data, likely reflecting the impact of a local (undiluted) source on the point measurement.

The PTR-MS and DOAS data were averaged over fixed 10 min intervals and the data compared in a regression analysis. Averages were calculated if there where more than 3 data points in the interval. Other averaging intervals were investigated and it was determined that time averaging did not influence the slope of the PTR-MS versus DOAS linear regression. Longer averaging intervals reduced the scatter and increased the correlation coefficient as expected. Figure 9 shows the correlation between these techniques for the 10 min averaged data. Compared to the PTR-MS versus GCFID plots, a higher degree of scatter is evident, possibly a reflection of the inherent differences in the spatial sampling between point and long path measurements. The data were fit using both monovariate and bivariate linear regressions using the standard deviation of the $10 \mathrm{~min}$ averages as weighting. There were some significant differences in the derived slope and intercept between the two regression methods. The results are tabulated in Table 4. It is clear that the relatively large dynamic range spanned by the data and the presence of a few points at high mixing ratios influence the monovariate linear regression fits to the point where the fits sometimes did not represent the bulk of the data. A good example is the phenol plot. The styrene and cresol data were too scattered for the bivariate regression fit to converge properly. This is probably due to the quite heterogeneous picture in the styrene time series data, which did not show the pronounced traffic pattern of high concentrations during morning rush hour, 
Table 4. PTR-MS versus DOAS regression fits parameters to ambient data.

\begin{tabular}{lllllll}
\hline & \multicolumn{3}{c}{ Weighted Monovariate Fit } & \multicolumn{2}{c}{ Weighted Bivariate Fit } \\
& slope & intercept & $r$ & slope & intercept & Excluded data \\
\hline benzene & $1.22 \pm 0.01$ & $0.39 \pm 0.01$ & 0.614 & $1.02 \pm 0.04$ & $0.45 \pm 0.13$ & DOAS $<0.7$ \\
toluene & $0.60 \pm 0.003$ & $0.81 \pm 0.03$ & 0.554 & $0.63 \pm 0.002$ & $0.93 \pm 0.05$ & \\
C $_{2}$-alkylbenzenes & $0.59 \pm 0.002$ & $0.04 \pm 0.01$ & 0.583 & $0.48 \pm 0.004$ & $0.84 \pm 0.06$ & DOAS $<1$ \\
naphthalene & $0.91 \pm 0.002$ & $-0.03 \pm 0.001$ & 0.537 & $0.60 \pm 0.83$ & $0.03 \pm 0.32$ & \\
styrene & $0.72 \pm 0.01$ & $0.05 \pm 0.003$ & 0.612 & & & DOAS $<0.1$ \\
cresols & $1.06 \pm 0.01$ & $0.01 \pm 0.01$ & 0.557 & & & DOAS $<0.01$ \\
phenol & $0.80 \pm 0.01$ & $0.06 \pm 0.001$ & 0.533 & $0.68 \pm 1.0$ & $0.09 \pm 0.32$ & DOAS $<0.02$ \\
\hline
\end{tabular}
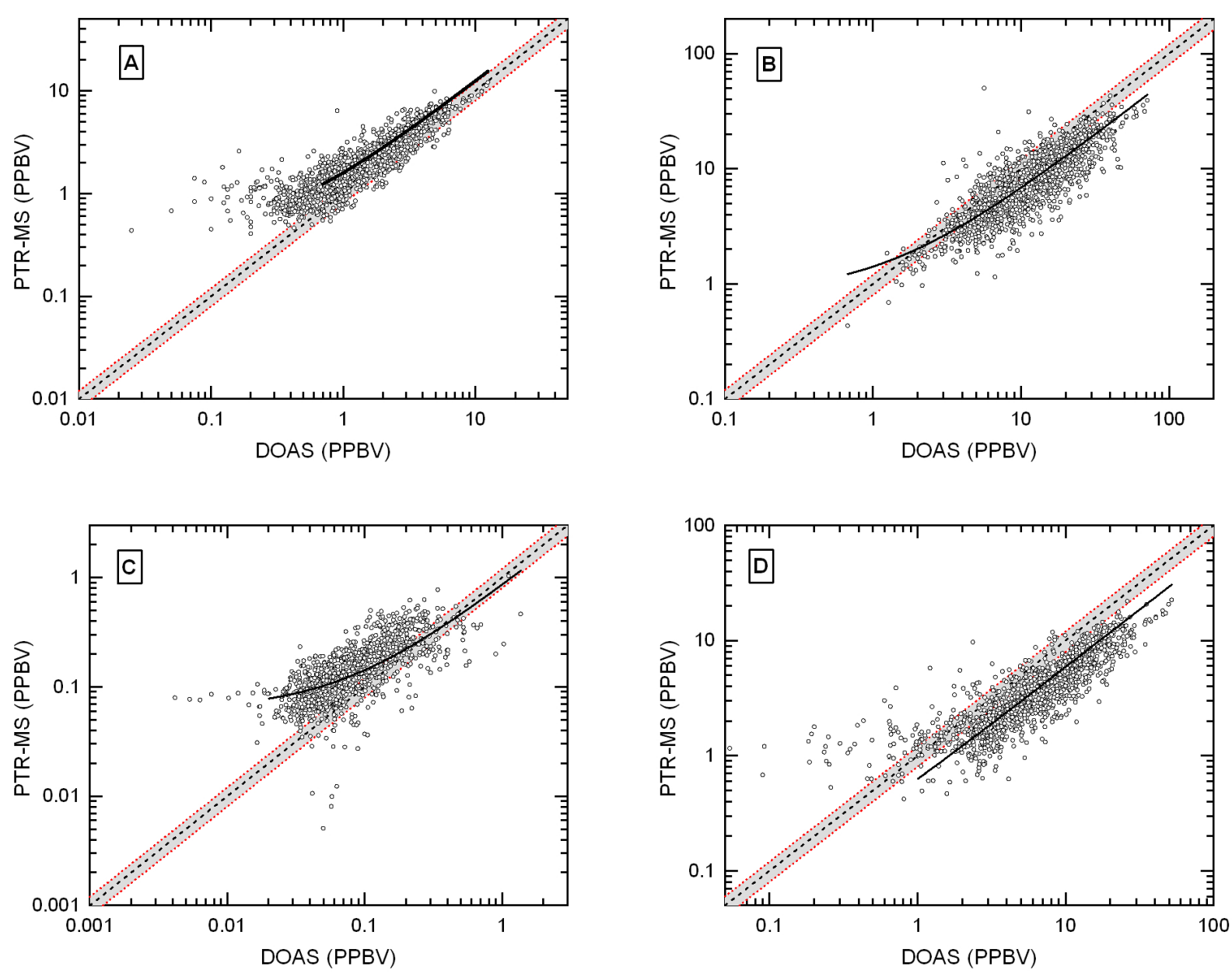

Fig. 9. PTR-MS versus DOAS (a) benzene (b) toluene (c) phenol (d) $\mathrm{C}_{2}$-alkylbenzenes. Plotted are 10 min averaged data. Monovariate linear regression fits are indicated by the solid black line. The dashed line is the $1: 1$ line bounded by $\pm 20 \%$ range (grey shading).

followed by dilution during the day that was typical for the other aromatics. Sources other than traffic seem to contribute to the abundance of styrene in Mexico City and affect the DOAS and point measurements at different times, leading to poorer correlations. There is also the potential for positive interferences in the PTR-MS data that contribute to the scatter in the styrene and cresol data.
An alternative approach for comparing these datasets is to examine the frequency distribution of the PTR-MS/DOAS ratio and examine the dependence of this ratio on other factors such as mixing ratio levels, time of day and wind direction. Figure 10 shows the PTR-MS/DOAS ratio versus the DOAS measurement together with histograms of the ratio. In this analysis, the PTR-MS benzene data were corrected 
for contributions from fragmenting alkylbenzenes using the Rogers et al. (2006) algorithm. The histograms are restricted to data where the DOAS measurements were above detection limits as defined in the experimental section. Toluene was the only species measured where the data from both instruments were clearly above detection limits during the entire study period. There was a clear tendency in the data for the PTRMS/DOAS ratio to increase with decreasing DOAS mixing ratios. The histograms of the PTR-MS/DOAS ratio were fit with a log-normal curve and the mean ratio and standard deviation determined by the fit are given in Table 5. The mean ratio agreed well with the slope of the bivariate fit regressions for benzene, toluene, $\mathrm{C}_{2}$-alkylbenzenes and naphthalene. For benzene, the histogram fit yielded a mean ratio of 0.99 , suggesting that the fragmentation of ethylbenzene and propylbenzene was properly accounted for in the PTR-MS benzene data by the Rogers et al. (2006) algorithm. For most species the PTR-MS/DOAS ratio was significantly less than 1 . The mean ratios for toluene, $\mathrm{C}_{2}$-alkylbenzenes and naphthalene were $0.62,0.50$ and 0.57 , respectively. The styrene ratio was determined to be 0.77 . The cresol ratio was 0.88 and we note again that the DOAS was measuring p-cresol while the PTRMS measures the sum of all cresol isomer and, thus, a ratio $>1$ would be anticipated. The phenol regression fits gave slopes less than 1, in contrast to the mean ratio found from the histogram plots. From Fig. 9, it is clear that the bulk of the PTR-MS phenol data lies above the 1:1 line and, thus, the mean ratio value of 1.49 is a better representation of the level of agreement. The fidelity of phenol, cresol and naphthalene measurements by PTR-MS is not well established and this is the first reported comparison with another technique. It is difficult to draw conclusions about the analytical fidelity for these species by either technique since there is such a large amount of scatter in the data and it is not clear whether this scatter is driven by spatial gradients or analytical problems or a combination of both. Given that the corrected benzene data displayed a mean PTR-MS/DOAS ratio of 0.99, it is somewhat surprising that the toluene and $\mathrm{C}_{2}$-alkylbenzene ratios were so much lower. All these species have significant roadway sources but it is possible that additional sources of toluene and xylenes from paint shops or other businesses using solvents may be important in the sector through which the DOAS beam passes.

\subsubsection{Influence of wind direction}

To better understand the general nature of the approximate factor of 2 discrepancy between the DOAS and PTR-MS toluene measurements, the data were sorted according to the time of day and the wind direction measured on the flux tower (37-m height). Of the species measured in common, toluene was considered to be the most accurately determined; being free from major interferences in both techniques and above detection limits during the entire study period. Lab tests also demonstrated that the PTR-MS calibration standard
Table 5. Log-normal fit parameters to histograms of PTR-MS to DOAS data ratios.

\begin{tabular}{lcc}
\hline & \multicolumn{2}{c}{ PTR-MS/DOAS Ratio } \\
\hline Species & Mean & $\sigma$ \\
\hline benzene & 0.99 & 0.288 \\
toluene & 0.62 & 0.299 \\
C $_{2}$-alkylbenzenes & 0.50 & 0.296 \\
naphthalene & 0.57 & 0.490 \\
styrene & 0.77 & 0.317 \\
cresols & 0.88 & 0.327 \\
phenol & 1.49 & 0.403 \\
\hline
\end{tabular}

was in agreement with the DOAS based method. Thus, ambient toluene data should be in good agreement. The discrepancy suggests a real difference between point and long path measurements due to spatial gradients in toluene mixing ratios. The toluene data were averaged over half-hour intervals and the ratio of the PTR-MS to DOAS values were calculated. It was clear that wind direction played some role in the level of agreement between the DOAS and PTR-MS. Figure 11 shows the frequency distribution of the DOAS/PTRMS toluene ratio sorted according to the wind rose quadrants. The frequency distributions from the south and east sectors displayed a similar shape and mode and these data were binned together, yielding a distribution with a mean PTR-MS to DOAS ratio of $0.59 \pm 0.01$. Likewise, the similar frequency distributions of the north and west quadrant data were grouped, yielding a mean ratio of $0.67 \pm 0.01$, significantly higher than the other data. The toluene measurements between the two techniques were in better agreement when the wind flow was from the north $\left(315^{\circ}\right.$ to $\left.45^{\circ}\right)$ or west $\left(225^{\circ}--315^{\circ}\right)$, however, there was still significant differences between them. On the local scale, major roadways lie to the east and south of the site in the general direction of the DOAS retro-reflector. VOC emission rates were generally larger in the eastern sector traversed by the DOAS beam line (Velasco et al., 2005). Since wind direction played only a small role in the level of agreement, we conclude that the DOAS measurements yielded higher toluene mixing ratios than point measurements from the top of the flux tower because the DOAS beam traversed a major toluene emissions area and was closer to the surface. Similarly, the spatial inhomogeneities in VOC sources may have contributed to the general discrepancy between PTR-MS and DOAS data for $\mathrm{C}_{2}$-alkylbenzenes, naphthalene, styrene and cresols.

The comparison of point and long path measurements raises the interesting issue of describing average urban concentrations of primary pollutants which may have very strong local concentration gradients. Such comparisons highlight spatial heterogeneity of pollutants on the local scale. The measurements made at the top of the tower were high 

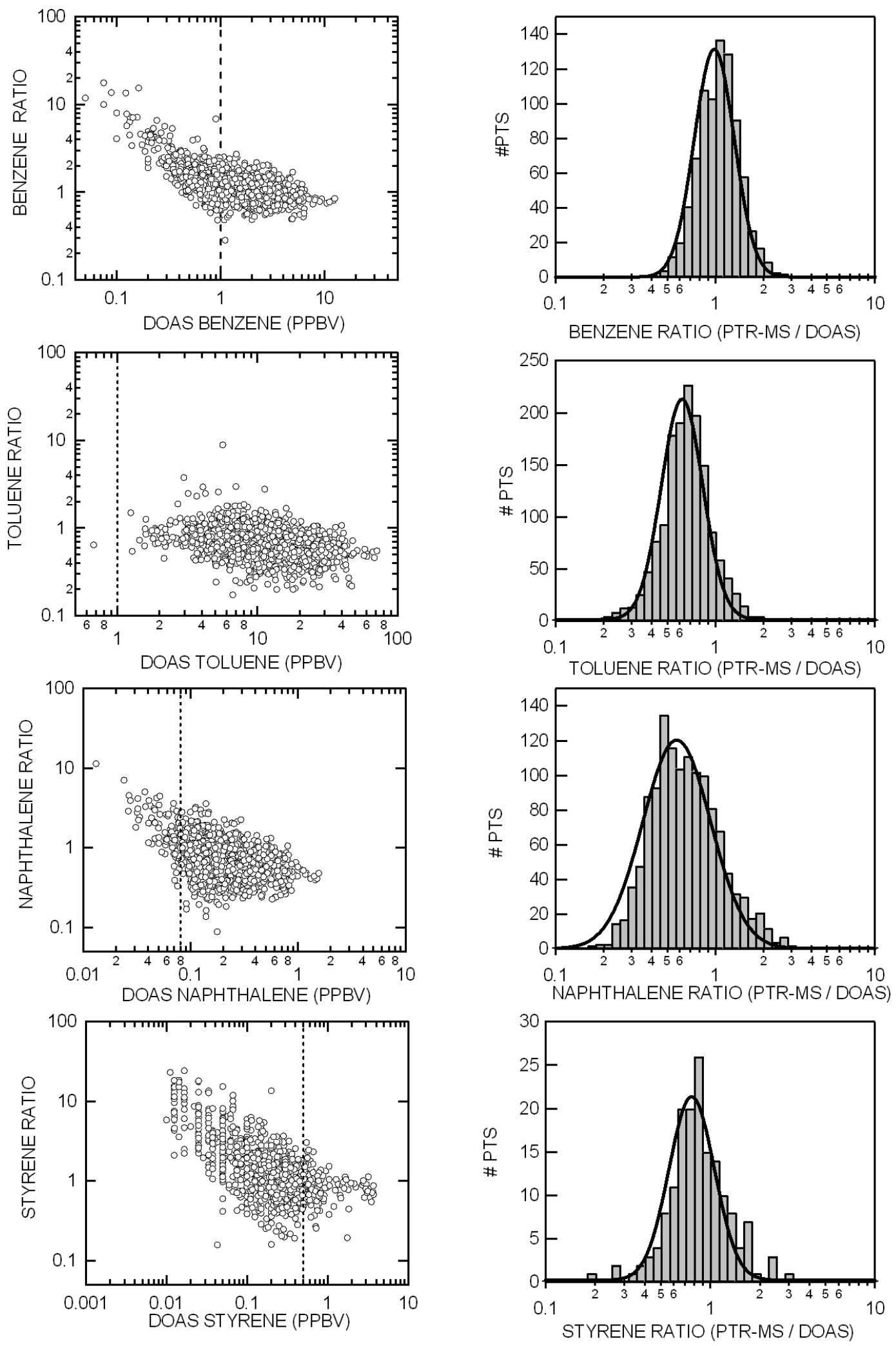

Fig. 10. The panels on the left display the PTR-MS to DOAS ratio versus DOAS for 10 min average data. The dashed line indicates the DOAS detection limit. The panels on the right display the corresponding histograms of the PTR-MS/DOAS ratio for those data where DOAS measurements were above the detection limit. The histogram plots were fitted with a log-normal distribution curve (solid line). 

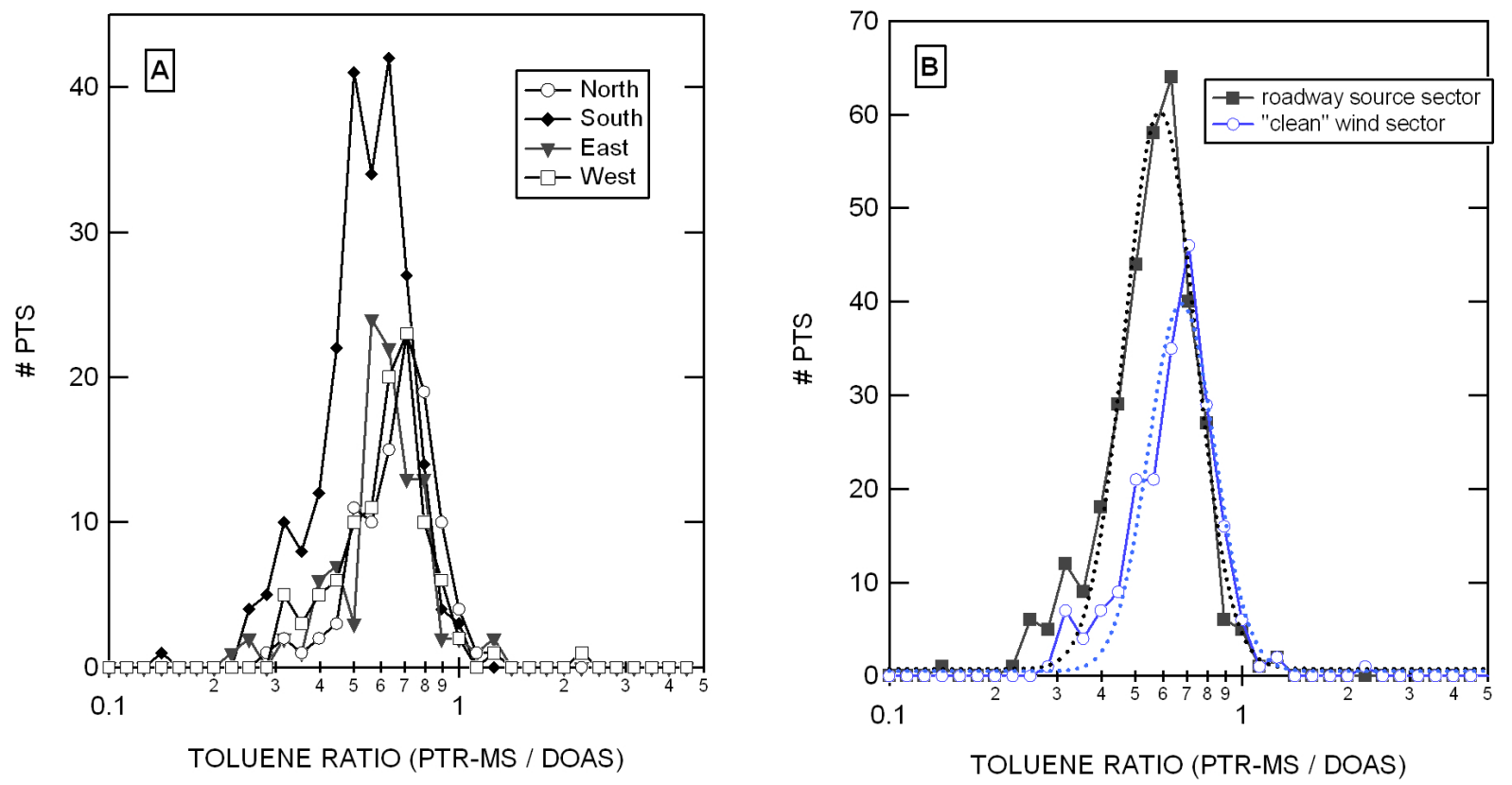

Fig. 11. Panel (A) shows frequency distributions of the ratio of the PTR-MS to DOAS toluene measurements sorted according to wind direction. Data are 1/2 h averages. In Panel (B) south and east wind sector data from panel (A) were combined as roadway source sector, north and west wind sector data were combined and plotted as "clean" sector data. Dashed lines correspond to the respective histograms.

enough above the roughness sublayer, in which emissions are blended by the urban turbulence, that the fetch was estimated to extend on average $1.3 \mathrm{~km}$. A maximum fetch of $5 \mathrm{~km}$ occurred at nighttime under stable conditions and a minimum of $500 \mathrm{~m}$ under unstable conditions (Velasco et al., 2005). Thus, when winds changed direction, the tower measurements responded to emission fluxes from the areas defined by the fetch. The DOAS beam inherently samples over a larger spatial scale than a point measurement, if measurements are conducted at comparable height. While all measurements were conducted above roof-top level, the DOAS beam was at a lower height and passed through a sector with high traffic emissions. We cannot rule out that vertical gradients, in addition to horizontal inhomogeneities driven by emissions, contribute to the systematic differences found between the open-path and point sampling techniques.

\section{Conclusions}

Measurements of aromatic compounds were made at the CENICA supersite, an urban area of Mexico City, from 3 April to 2 May 2003 by a PTR-MS instrument, a research grade DOAS instrument and by canister sampling followed by GC-FID analysis. The PTR-MS and canisters sampled from an inlet $37-\mathrm{m}$ above the ground, while the average DOAS beam height was $16-\mathrm{m}$ along a $430 \mathrm{~m}$ path length to the southeast. The PTR-MS benzene data were typically greater than GC-FID determinations, on average by a factor of $1.8 \pm 0.6$ for benzene mixing ratios $<4$ ppbv. At higher mixing ratios there was better agreement. The PTR-MS benzene data suffered a positive interference from ethylbenzene and propylbenzene, causing benzene to be over estimated by $\sim 16 \%$. The PTR-MS measurements of toluene, $\mathrm{C}_{2}$-alkylbenzenes and $\mathrm{C}_{3}$-alkylbenzenes were in reasonable agreement with the GC-FID data. This established the fidelity of PTR-MS data for these compounds and, therefore, a reasonable expectation that a comparison of PTRMS and DOAS data for toluene and $\mathrm{C}_{2}$-alkylbenzenes would also be in reasonable agreement. Good agreement was observed for benzene once the PTR-MS data were corrected for interferences from ethylbenzene and propylbenzene. The mean PTR-MS to DOAS ratio for benzene was 0.99. However, the PTR-MS and GC-FID data for toluene and $\mathrm{C}_{2}$ alkylbenzenes, sampled about $20 \mathrm{~m}$ above the mean height of the DOAS beam, tended to be lower than the DOAS data. On average, the difference was $\sim$ factor of 2 for the PTRMS data. Lab tests established that the DOAS and PTRMS calibrations for benzene, toluene, phenol, styrene, pxylene, ethylbenzene and 1,2,4-trimethlybenzene were consistent within $10 \%$. Higher DOAS values were, therefore, likely caused by vertical, in addition to horizontal, gradients in VOC concentrations. Toluene was the best determined compound, being free of major known interferences and always above detection limits for both instruments. An analysis of the toluene data revealed that the level of agreement between the PTR-MS and DOAS was somewhat dependent on wind direction. For the entire dataset, the PTR-MS/DOAS 
toluene ratio was found to be log-normally distributed, with a mean ratio of 0.62 . The toluene ratio was $0.59 \pm 0.01$ when the wind blew from the south and east quadrants, an area of major roadways, and $0.67 \pm 0.01$ when the wind blew from the cleaner north and west quadrants. Given this modest dependence on wind direction, and that the benzene data displayed good agreement, we conclude that non-roadway emissions of toluene, such as solvent use, were important in the sector through which the DOAS beam passed. PTRMS data for $\mathrm{C}_{2}$-alkylbenzenes were on average a factor of 0.50 lower than the DOAS data, consistent with the toluene data, again suggesting that non-roadway emissions were important. The DOAS data likely observed higher mixing ratios due to the difference in sampling height above roof-level and that the light path traversed an area where VOC emissions from non-roadway sources were important for these species. Given the near factor of 2 average difference between the DOAS and PTR-MS toluene data, the analysis highlights the issue of representative sampling in an urban environment. Spatial concentration gradients complicate the sampling of hydrocarbons and possibly other pollutants in urban areas for comparison with photochemical models.

Acknowledgements. A portion of the research was performed using EMSL, a national scientific user facility sponsored by the US Department of Energy's Office of Biological and Environmental Research and located at Pacific Northwest National Laboratory. Rainer Volkamer acknowledges support from the Camille and Henry Dreyfus Postdoctral Fellowship in Environmental Chemistry and the Alexander von Humboldt Foundation for a Feodor-Lynen Fellowship.

Edited by: C. E. Kolb

\section{References}

Apel, E. C., Calvert, J. G., and Fehsenfeld, F. C.: The nonmethane hydrocarbon intercomparison experiment (NOMHICE): Tasks 1 and 2, J. Geophys. Res., 99(D8), 16651-16664, 1994.

Apel, E. C., Calvert, J. G., Riemer, D., Pos, W., Zika, R., Kleindienst, T. E., Lonneman, W. A., Fung, K., Fujita, E., Shepson, P. B., Starn, T. K., and Roberts, P. T.: Measurements comparison of oxygenated volatile organic compounds at a rural site during the 1995 SOS Nashville intensive, J. Geophys. Res., 103(D17), 22295-22316, 1998.

Apel, E. C., Calvert, J. G., Gilpin, T. M., Fehsenfeld, F. C., Parrish, D. D., and Lonneman, W. A.: The nonmethane hydrocarbon intercomparison experiment (NOMHICE): Task 3, J. Geophys. Res., 104(D21), 26060-26086, 1999.

Apel, E. C., Calvert, J. G., Gilpin, T. M., Fehsenfeld, F. C., and Lonneman, W. A.: The nonmethane hydrocarbon intercomparison experiment (NOMHICE): Task 4, ambient air, J. Geophys. Res., 108(D9), 4300, doi:1029/202JD002936, 2003.

Axelsson, H., Eilard, A., Emanuelsson, A., Galle, B., Edner, H., Ragnarson, P., and Kloo, H.: Measurement of aromatic hydrocarbons with the DOAS technique, Appl. Spectrosc., 49, 1254$1260,1995$.
Bass, A. M. and Paur, R. J.: UV absorption cross-sections for ozone - the temperature dependence, J. Photochem., 17, 141$141,1981$.

de Gouw, J. and Warneke, C.: Measurement of volatile organic compounds in the Earth's atmosphere using proton transfer reaction mass spectrometry, Mass Spectrom. Rev., 26, 223-257, 2007.

Dzepina, K., Volkamer, R. M., Madronich, S., Tulet, P., Ulbrich, I. M., Zhang, Q., Cappa, C. D., Ziemann, P. J., and Jimenez, J. L.: Evaluation of recently-proposed secondary organic aerosol models for a case study in Mexico City, Atmos. Chem. Phys., 9, 5681-5709, 2009, http://www.atmos-chem-phys.net/9/5681/2009/.

Etzkorn, T., Klotz, B., Sorensen, S., Patroescu, I. V., Barnes, I., Becker, K. H., and Platt, U.: Gas-phase absorption cross sections of 24 monocyclic aromatic hydrocarbons in the UV and IR spectral ranges, Atmos. Environ., 33, 525-540, 1999.

Fally, S., Vandaele, A. C., Carleer, M., Hermans, C., Jenouvrier, A., Merienne, M. F., Coquart, B., and Colin, R.: Fourier transform spectroscopy of the $\mathrm{O}_{2}$ Herzberg bands, III. Absorption cross sections of the collision-induced bands and of the Herzberg continuum, J. Mol. Spectrosc., 204, 10-20, 2000.

Fayt, C. and van Roozendael, M.: WinDoas 2.1 Software User Manual, 2001.

Flores, E., Grutter, M., and Galle, B.: Open-path emission factors derived from DOAS and FTIR measurements in Mexico City Metropolitan Area, EOS T. Am. Geophys. Un., 85(47), Fall Meet., Suppl. Abstract A11A-0003, 2004.

Fujita, E., Harshfield, G., and Sheetz, L.: Performance audits and laboratory comparisons for SCOS97-NARSTO measurements of speciated volatile organic compounds, Atmos. Environ., 37, Supplement No. 2, S135-S147, 2003.

Hansel, A., Jordan, A., Holzinger, R., Prazeller, P., Vogel, W., and Lindinger, W.: Proton transfer reaction mass spectrometry: online trace gas analysis at the ppb level, Int. J. Mass Spectrom., 149/150, 609-619, 1995.

Jobson, B. T., Berkowitz, C. M., Kuster, W. C., Goldan, P. D., Williams, E. J., Fehsenfeld, F. C., Apel, E. C., Karl, T., Lonneman, W. A., and Reimer, D.: Hydrocarbon source signatures in Houston Texas: Influence of the petrochemical industry, J. Geophys. Res., 109, D24305, doi:10.1029/2004JD004887, 2004.

Jenouvrier, A., Merienne, M. F., Coquart, B., Carleer, M., Fally, S., Vandaele, A. C., Hermans, C., and Colin, R.: Fourier transform spectroscopy of the $\mathrm{O}_{2}$ Herzberg bands - I. Rotational analysis, J. Mol. Spectrosc., 198, 136-162, 1999.

Jobson, B. T., Alexander, M. L. , Maupin, G. D., and Muntean, G. G.: On-line analysis of organic compounds in diesel exhaust using proton transfer reaction mass spectrometry (PTR-MS), Int. J. Mass Spectrom., 245, 78-89, 2005.

Karl, T., Jobson, T., Kuster, W. C., Williams, E., Stutz, J., Shetter, R., Hall, S. R., Goldan, P., Fehsenfeld, F., and Lindinger, W.: Use of proton transfer reaction mass spectrometry to characterize volatile organic compound sources at the La Porte super site during the Texas Air Quality Study 2000, J. Geophys. Res, 108(d16), 4508, doi:10.1029/2002/2002JD003333, 2003.

Kleinman, L. I., Springston, S. R., Daum, P. H., Lee, Y.-N., Nunnermacker, L. J., Senum, G. I., Wang, J., Weinstein-Lloyd, J., Alexander, M. L., Hubbe, J., Ortega, J., Canagaratna, M. R., and Jayne, J.: The time evolution of aerosol composition over the 
Mexico City plateau, Atmos. Chem. Phys., 8, 1559-1575, 2008, http://www.atmos-chem-phys.net/8/1559/2008/.

Kuster, W. C., Jobson, B. T., Karl, T., Riemer, D., Apel, E., Goldan, P. D., and Fehsenfeld, F. C.: Intercomparison of volatile organic carbon measurement techniques and data at La Porte during the TexAQS2000 air quality study, Environ. Sci. Technol., 38, 221228, 2004.

Lagg, A., Taucher, J., Hansel, A., and Lindinger, W.: Applications of proton transfer reactions to gas analysis, Int. J. Mass. Spectrom., 134, 55-66, 1994.

McKinley, G., Zuk, M., and Hojer, M.: Quantification of local and global benefits from air pollution control in Mexico City, Environ. Sci. Technol., 39, 1954-1962, 2005.

Merienne, M. F., Jenouvrier, A., Coquart, B., Carleer, M., Fally, S., Colin, R., Vandaele, A. C., and Hermans, C.: Fourier transform spectroscopy of the $\mathrm{O}_{2}$ Herzberg bands - II. Band oscillator strengths and transition moments, J. Mol. Spectrosc., 202, 171193, 2000.

Merienne, M. F., Jenouvrier, A., Coquart, B., Carleer, M., Fally, S., Colin, R., Vandaele, A. C., and Hermans, C.: Improved data set for the Herzberg band systems of ${ }^{16} \mathrm{O}_{2}$, J. Mol. Spectrosc., 207, 120,2001

Molina, L. T., Kolb, C. E., de Foy, B., Lamb, B. K., Brune, W. H., Jimenez, J. L., Ramos-Villegas, R., Sarmiento, J., ParamoFigueroa, V. H., Cardenas, B., Gutierrez-Avedoy, V., and Molina, M. J.: Air quality in North America's most populous city overview of the MCMA-2003 campaign, Atmos. Chem. Phys., 7, 2447-2473, 2007, http://www.atmos-chem-phys.net/7/2447/2007/.

Parrish, D. D., Trainer, M., and Young, V.: Internal consistency tests for evaluation of measurements of anthropgenic hydrocarbons in the troposphere, J. Geophys. Res, 108, 22339-22359, 1998.

Platt, U.: Monitoring by Spectroscopic Techniques, edited by: Sigrist, M. W., Wiley \& Sons, New York, 1994.

Rogers, T. M., Grimsrud, E. P., and Herndon, S. C.: On-road measurements of volatile organic compounds in the Mexico City metropolitan area uisng proton transfer reaction mass spectrometry, Int. J. Mass Sprectrom., 252, 26-37, 2006.

Shirley, T. R., Brune, W. H., Ren, X., Mao, J., Lesher, R., Cardenas, B., Volkamer, R., Molina, L. T., Molina, M. J., Lamb, B., Velasco, E., Jobson, T., and Alexander, M.: Atmospheric oxidation in the Mexico City Metropolitan Area (MCMA) during April 2003, Atmos. Chem. Phys., 6, 2753-2765, 2006, http://www.atmos-chem-phys.net/6/2753/2006/.

Slemr, J., Slemr, F., Partridge, R., D’Souza, H., and Schmidbauer, N.: Accurate measurements of hydrocarbons in the atmosphere (AMOHA): Three European intercomparions, J. Geophys. Res., 107(D19), 4409, doi:10.1029/2001JD001357, 2002.

Spanel, P. and Smith, D.: Selected ion flow tube studies of the reactions of $\mathrm{H}_{3} \mathrm{O}^{+}, \mathrm{NO}^{+}$, and $\mathrm{O}_{2}^{+}$with several aromatic and aliphatic hydrocarbons, Int. J. Mass Spectrom., 181, 1-10, 1998.
Stutz, J. and Platt, U.: Numerical analysis and estimation of the statistical error of differential optical absorption spectroscopy measurements with least-squares methods, Appl. Optics, 35, 60416053, 1996.

Su, T. and Chesnavich, W. J.: Parameterization of the ion-molecule collision rate constant by trajectory calculations, J. Chem. Phys., 76, 5183-5185, 1982.

Su, T.: Erratum: Trajectory calculations of ion-polar molecule capture rate constants at low temperatures, J. Chem. Phys., 89, 5355, 1989.

Velasco, E.: Estimates for biogenic non-methane hydrocarbons and nitric oxide emissions in the Valley of Mexico, Atmos. Environ. 37, 625-637, 2003.

Velasco, E., Lamb, B., Pressley, S., Allwine, E., Westberg, H., Jobson, T., Alexander, M., Prazeller, P., Molina, L., and Molina, M.: Flux measurements of volatile organic compounds from an urban landscape, Geophys. Res. Lett., 32, L20802, doi:10.1029/2005GL023356, 2005.

Velasco, E., Lamb, B., Westberg, H., Allwine, E., Sosa, G., ArriagaColina, J. L., Jobson, B. T., Alexander, M. L., Prazeller, P., Knighton, W. B., Rogers, T. M., Grutter, M., Herndon, S. C., Kolb, C. E., Zavala, M., de Foy, B., Volkamer, R., Molina, L. T., and Molina, M. J.: Distribution, magnitudes, reactivities, ratios and diurnal patterns of volatile organic compounds in the Valley of Mexico during the MCMA 2002 \& 2003 field campaigns, Atmos. Chem. Phys., 7, 329-353, 2007, http://www.atmos-chem-phys.net/7/329/2007/.

Volkamer, R., Geyer, A., Etzkorn, T., and Platt, U.: Correction of the oxygen interference with UV-spectroscopic (DOAS) measurements of monocyclic aromatic hydrocarbons in the atmosphere, Atmos. Environ., 32, 3731-3747, 1998.

Volkamer, R., Molina, L. T., Molina, M. J., Shirley, T., and Brune, W. H.: DOAS measurement of glyoxal as an indicator for fast VOC chemistry in urban air, Geophys. Res. Lett., 32, L08806, doi:10.1029/2005GL022616, 2005.

Volkamer, R., Jimenez, J. L, San Martini, F., Dzepina, K., Zhang, Q., Salcedo, D., Molina, L. T., Worsnop, D. R., and Molina, M. J.: Secondary organic aerosol formation from anthropogenic air pollution: rapid and higher than expected, Geophys. Res. Lett., 33, L17811, doi:10.1029/2006GL026899, 2006.

Volkamer, R., San Martini, F., Salcedo, D., Molina, L. T., Jimenez, J. L., and Molina, M. J.: A missing sink for gas-phase glyoxal in Mexico City: Formation of secondary organic aerosol, Geophys. Res. Lett., 34, L19807, doi:10.1029/2007GL030752, 2007.

Volz-Thomas, A., Slemr, J., Konrad, S., Schmitz, T. H., Apel, E. C., and Mohnen, V. A.: Quality assurance of hydrocarbon measurements for the German tropospheric research focus (TFS), J. Atmos. Chem., 42, 255-279, 2002.

Zhao, J. and Zhang, R.: Proton transfer reaction rate constants between hydronium ion $\left(\mathrm{H}_{3} \mathrm{O}^{+}\right)$and volatile organic compounds, Atmos. Environ., 38, 2177-2185, 2004. 